\title{
Educational Reform of Mechanical Manufacturing Technology Course Aiming at Cultivating Innovative Ability
}

\author{
Hansong Yang \\ Huanghe Science and Technology College \\ Zhengzhou, China
}

\author{
Fating Zhang \\ Huanghe Science and Technology College \\ Zhengzhou, China
}

\author{
Luoming Zhang \\ Huanghe Science and Technology College \\ Zhengzhou, China
}

\begin{abstract}
Mechanical Manufacturing Technology Basics is a basic technological course that is supposed to be learnt by all specialties of mechanical engineering subject. In order to meet the market's requirement for talents, cultivating applied innovative talent has become a subject to be discussed in course teaching. In the process of course teaching, we should optimize the contents of curriculum system and cultivate students' innovative and applied capability from the viewpoint of students' applied and innovation capability; meanwhile, we should also reform our teaching method, and enable students to innovate and apply in their learning process.
\end{abstract}

Keywords-innovation capability; mechanical manufacturing; curriculum reform

\section{INTRODUCTION}

Mechanical Manufacturing Technology Basics is an important specialized course that is supposed to be learnt by all specialties of mechanical engineering subject. The course is closely knitted to the four parts of mechanical manufacturing technique system to teach students, mainly containing theory of metal cutting, metal cutting tools, metal cutting machine, and design principle of machine jig, schedule design of mechanical processing technique and mechanical assembly technology, which is a basic mechanical course with strong technicality. Through such a course, students can learn the basic principle and method of mechanical processing, design of machine jig, machining process draft and training of assembly technology and skills. Meanwhile, students will have basic ability and skill to resolve practical engineering problems and process machinery. Therefore, learning this course takes an important role in cultivating students' basic manufacturing theory and skills.

According to the features and contents of this course, in order to cultivate students' innovation capability, we can know that this course combines knowledge and skills, takes advantage of various methods such as experimentation, practice and design to strengthen cultivating knowledge and capability. The following diagram is the teaching structure of knowledge and capability cultivation "Fig. 1".

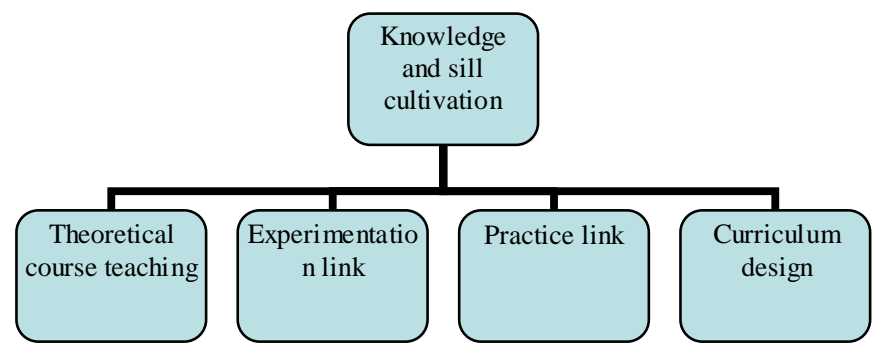

Fig. 1. The teaching structure of knowledge and capability cultivation.

\section{Problems in Traditional Teaching Process}

Since this course is a basic specialized technical course based on practice, teaching must be combined with production practice or experimentation; and in line with curriculum design, what they have learnt should be consolidated. However, traditional teaching method is respectively dull and boring; teachers conduct teaching activities by blackboard-writing, simple model and multimedia. As for those practical contents, blackboard-writing and model cannot help students understand them. As a result, students cannot understand it or their understanding deviates. What's more, there are few periods for experimentation and design; students do not have much access to factories or real things; what they have learnt cannot be applied to practice. Therefore, traditional teaching method cannot help students know the difficulties in manufacturing, and cannot enable them to grasp practical knowledge to resolve real problems.

In order to propel the reform of talent cultivation pattern, improve students' operational capability and ability to resolve practical engineering problems and cultivate engineering technical talents and excellent field engineers, we must reform the teaching method of Mechanical Manufacturing Technology Basics 


\section{CURRICUlum Contents AND TEACHING Method REFORM}

In order to highlight key points and strengthen students' capability cultivation, we should first of all do some adjustment on curriculum content. Secondly, we should alter the traditional cramming method of teaching, combine teaching process and plant workshops and add some applied innovative content to the course.

\section{A. Integrating Curriculum Content and Teaching Method}

According to the nature of course and relationships among courses, we should integrate the curriculum contents, cut down some material and reform our teaching pattern; specific approaches are as follows.

- Adjusting the curriculum content of selecting cutter materials; directly introducing the materials of cutters or what kind of material is suitable for making a certain cutter, how to select different cutters according to specific workpiece etc.

- The content of metal-cutting machine mainly introduces structure and transmission relation of typical machine tools (lathes) and just gives a brief introduction to other machine tools such as miller, grinder; adding contents of advanced processing machine tool such as numerical control machine, machining center and multi-axis machine tool enables students to have a better understanding of modern processing machine tools.

- On-the-spot teaching: parts of the course content are set in the plant, i.e., teachers give a lecture on the production site and simultaneously they demonstrate their theory, which helps students understand and master the knowledge in operation. For example, metal cutting process, cutter's angulation, material cutting and processing can be taught in the factories, and student can learn course content on spot.

- After being given lecture on basic theories of abrasive machining, machine tool structure and jig design, students should immediately enter laboratories to verify what they have learnt and to deepen the theoretical their knowledge.

- In teaching process, we should adopt various forms of teaching interaction to cultivate students' capability to think independently and resolve problems; then, students can deal with practical problems with their knowledge. We should also guide students to generalize and summarize what they have learnt, to catch key points and to consolidate their knowledge.

- Double-tutor system in teaching: we can adopt doubletutor system in curriculum design step, i.e., teachers in college and in enterprises or factories co-instruct students' practice step. Mainly instructed by the teachers in enterprises, students can adopt enterprises' real problem in their jig design and process design, which is a better training for students.

\section{B. Increasing the Intensity of Practice}

1) Cultivation of operation ability: This course is a specialized course based on practice; therefore, in the whole teaching process, students should continuously conduct practice and experiments. Course contents should be directly associated with real production; apart from wall drawings, multimedia and other approaches, students should do operation verification and experimentation in factories. For example, cutter's geometric angle is very difficult for student to understand it only by lecturing theories. Thus, in this teaching process, students should hold the cutter and point out its geometric angle, and they should also grind by themselves, which enables students to master its structure and deepen their understanding. We give a lecture on the jig, except that we make them know the function of the jig in processing, students should also choose some typical parts, setting elements, then according to the requirements to select other parts and clamp system to assembly required jigs. If permitted, students should put jigs into machine tools to use them, to make students know the jig's function in machining. Through these steps, students can have a better understanding to the contents of course; meanwhile, their operational ability, practical skills and other capabilities are also fully trained.

2) Reform of curriculum design: Curriculum design is an essential comprehensive step in the course, playing an important role in teaching activities. However, this step is based on student's completion of production practice. We should increase the periods and contents of curriculum design and divide process and jig curriculum design into machine tool jig curriculum design and manufacturing process curriculum design. All spare parts of jigs come from the real products of plant, and the jigs can be a certain process jig of a part to jig of several processes; the parts are also enriched, and students will not have same questions anymore. Questions of process curriculum design are also the real products of factories, and students can decide all processes on their own, and teachers comparatively explains the processes according to factories' process contents, then students can master the real method to map out process route. The objects of this step are real parts of factories; first we should find out several typical parts and make students to accomplish a certain part's technological procedures in group, and every member of the group completes one procedure. Students are required to finish the following items to their own procedure: selecting cutter, selecting machine tool, calculating cutting parameter and designing jigs of the procedure; meanwhile, they are also required to complete one technological procedure card, one operational card, blank drawing, and jig assembly drawing of certain process, parts drawing of main parts, at last, a curriculum design instruction. Through this step, students can have real improvement on their design, calculation, drawing making and process route capability. This step not only cultivates students' practical ability to resolve problems, but also lays a certain foundation for their graduation project. 
3) Production practice: Production practice is a significant teaching step in the course. This step can help students understand and master basic theoretical knowledge, and it is also the first step for student to enter the society and have actual contact with production activities. Students' theories by learning and knowledge by practice cannot always resolve all problems in their textbook. For example, in theoretical teaching, concepts such as production line, procedure, step, composite step can easily be expressed, but students can hardly understand them; by production practice, they can easily understand what is production line, procedure, step, composite step, what mass production is, what the relation between theoretical knowledge and enterprises is and how to conduct enterprises' production activities. Usually, this step is arranged in summer break after the course is over, in YTO, for 2 weeks. Contents to be accomplished include about 20 items, such as casting, forging, machining and stamping. Students are required to record, discuss and summarize every step, then draw the conclusion.

\section{Reforming of Assessment Method}

1) The major adjustments of this course are as follows:Curriculum assessment consists of the following aspects.

- Theory test: $40 \%$

- Practice —operational capability: $30 \%$

- Curriculum design and innovative experiment: $30 \%$

- Grade of production practice is calculated separately.

2) Major contents and features of assessment: Theory test aims to examine students' ability to analyze and resolve practical engineering problems, not memorizing or calculating contents; operational capability is mainly about practical operation, such as design and construction of built-up jig, sharpener and dismounting of machine tools, and the grades are evaluated on their familiarity; grades of curriculum design are determined by the rationality of jig design and validity of process route.

\section{CONCLUSION}

This course is reformed in teaching process. On the basis of basic theories, combined with practice, practical training and curriculum design, students can have a better understanding of basic knowledge; meanwhile, their operational capability and ability to resolve practical engineering problems are truly improved. Compared with the former students, students' performance is stably and gradually improved.

\section{ACKNOWLEDGMENT}

This paper is a subsidized project sponsored by National College Students' Off-Campus Practice Base, Undergraduate Engineering Education in Ordinary Colleges Training Mode Reform Pilot of Henan Province, Universities' and Colleges' "Specialty Comprehensive Reform Pilot" Project,
Characteristic Specialties of Henan Province and Reform Research on Talent Cultivation Pattern of Huanghe $S \& T$ College.

\section{REFERENCES}

[1] Zhang Zhe, The Discussion of the Curriculum Reform of mechanical manufacturing technology, Journal of Zhangjiakou Vocational and Technical College.Vol.22,pp.70-71,2009.

[2] Yu Ying-hua,Zhang Xing-yuan. Reform and Practice in the Basic Course Design of Mechanism Manufacture Technology. Experiment Science \& Technology.Vol.7,pp.94-97,2009.

[3] Xu Feng, Zuo Dunwen. Study on teaching reform of mechanical manufacturing technology course. Journal of Higher Education Management. Vol .1 ,pp.90-93,2007.

[4] Yang Xiao - fan, Zheng Tian yi. Reform and Practice of Mechanism Manufacture Technology Basis. Journal of $\mathrm{Ji}$ mei University. Vol .1,pp94-96,2005.

[5] Han Bian-zhi, Wang Dong, Zhang Yin-xi. Trial and Reform in the Manufacturing Technology Foundation Course Based on the Ability Training. Journal of Taiyuan University of technology. Vol. 29,pp.8688,2011 . 